\title{
An efficient method for miRNA detection and localization in crop plants
}

\section{Flor de Fátima Rosas-Cárdenas ${ }^{1,2}$, Rocío Escobar-Guzmán ${ }^{1}$, Andrés Cruz-Hernández ${ }^{3}$, Nayelli Marsch-Martínez ${ }^{4}$ and Stefan de Folter ${ }^{1}{ }^{*}$}

\author{
Laboratorio Nacional de Genómica para la Biodiversidad, Centro de Investigación y de Estudios Avanzados del Instituto Politécnico Nacional, Guanajuato \\ México \\ 2 Centro de Investigación en Biotecnología Aplicada del Instituto Politécnico Nacional, Tlaxcala, México \\ ${ }^{3}$ Facultad de Ingeniería, Universidad Autónoma de Querétaro, Querétaro, México \\ ${ }^{4}$ Departamento de Biotecnología y Bioquímica, Centro de Investigación y de Estudios Avanzados del Instituto Politécnico Nacional, Guanajuato, México
}

\section{Edited by:}

Clelia De-la-Peña, Centro de

Investigación Científica de Yucatán,

Mexico

\section{Reviewed by:}

Serena Varotto, University of Padova Italy

Norberto Daniel lusem, Universidad de Buenos Aires, Argentina

\section{*Correspondence:}

Stefan de Folter, Laboratorio Nacional de Genómica para la Biodiversidad Centro de Investigación y de Estudios Avanzados del Instituto Politécnico Nacional, Km. 9.6 Libramiento Norte, Carretera Irapuato-León, CP 36821

Irapuato, Guanajuato, México

e-mail:sdfolter@langebio.

cinvestav.mx
microRNAs are a class of non-coding small RNAs (sRNAs) that are important regulators of gene expression at the post-transcriptional level by mRNA cleavage or translation inhibition. Another class of sRNAs are siRNAs, which also regulate gene expression but by causing DNA methylation. This epigenetic regulatory role has been observed for some miRNAs as well. The use of sRNAs allows the development of biotechnological applications in plants. To develop these types of applications, and to better understand the natural roles they play, it is important to be able to detect and to localize these sRNAs at the plant tissue level. Sometimes, in crop plants this can be challenging. Therefore, we developed a tissue printing hybridization protocol for easy and efficient detection of sRNAs and demonstrate this by the analysis of the spatio-temporal expression patterns of the miRNAs miR159 and miR164 in fruits of various crop plants. Moreover, we show the possibility to also detect the expression of miRNAs in fruit juice using a dot blot hybridization approach.

Keywords: tissue-printing, miRNA detection, hybridization, fruits, miR164

\section{INTRODUCTION}

microRNAs (miRNAs) are a class of small RNAs (sRNAs) that are fundamental regulatory elements of eukaryotic genomes (Voinnet, 2009) and their widespread conservation and divergence in the plant kingdom has been demonstrated (Chavez Montes et al., 2014). Detection of the spatio-temporal expression of miRNAs is critical to understand their function (van Rooij, 2011). Several techniques such as Northern-blot hybridization (Pall and Hamilton, 2008), microarray analysis (Yin et al., 2008), stem-loop RT-PCR analysis (Chen et al., 2005), or sRNA-seq analysis (Chavez Montes et al., 2014) permit the identification of miRNA expression patterns, which may suggest their involvement in certain biological processes. Besides these advantages, a drawback of these techniques is the lack of information about the actual localization of the miRNA in the tissue or organ itself, which is important for understanding the biological function of the miRNA.

A technique overcoming this drawback is in situ hybridization, which also allows the detection of miRNAs in thin tissue sections using a labeled complementary probe against the miRNA of interest (Kidner and Timmermans, 2006; Várallyay and Havelda, 2011). Nevertheless, the generation of thin tissue sections from large tissues using paraffin-embedding or cryosections may be challenging. Tissue printing in nitrocellulose or nylon membranes is a technique employed to study the localization of proteins, nucleic acids, and soluble metabolites from freshly cut tissue slices. Tissue printing has been defined as 'the art and science of visualizing cellular material and information that are transferred to a receptive surface when the cut surfaces of section of tissues or organs are pressed against such a surface' (Varner and Ye, 1994). This technique does not require RNA extraction or the preparation of thin tissue sections, and it allows the simultaneous analysis of many samples. Therefore, this technique is especially convenient for large tissues or organs, such as fleshy fruits that are often difficult to section for in situ hybridizations. Tissue printing in combination with hybridization has been used successfully to determine mRNA and protein localization in several studies (Holland et al., 2000; Qu et al., 2003; Jolie et al., 2010; Pluskota et al., 2011; Esteves et al., 2013; Mochizuki and Ohki, 2015). However, to date almost no examples have been reported for the detection of miRNAs in plants using tissue printing (e.g., Rosas-Cárdenas et al., 2015).

Here we report a protocol for tissue printing combined with hybridization in order to detect and to localize known miRNAs at the tissue level in different species. Although we focused mainly on fruits, this protocol may be used for other fleshy tissues as we demonstrate here by detecting miRNAs in floral buds. Moreover, we show also the possibility to detect the expression of miRNAs in fruit juice using a dot blot hybridization approach.

\section{MATERIALS AND METHODS PLANT MATERIAL}

Fleshy fruits were purchased at the local market. Agave buds (Agave atrovirens) were collected at the Centro de Investigación y de Estudios Avanzados del Instituto Politécnico Nacional 
(CINVESTAV-IPN), Irapuato. The tissues were washed and dried at room temperature.

\section{REAGENTS}

Nylon membrane (Hybond NX; Amersham/Pharmacia, cat. no. RPN303T)

3MM Whatman ${ }^{\circledR}$ chromatography paper

1-Methylimidazole (Sigma-Aldrich)

1-ethyl-3-(3-dimethylaminopropyl) carbodiimide (EDC;

Sigma-Aldrich)

Rapid-hyb Buffer (GE Healthcare)

EasyTides ${ }^{\circledR}$ Adenosine $5^{\prime}$-triphosphate, $\left(\gamma-{ }^{32} \mathrm{P}\right)-6000 \mathrm{Ci} / \mathrm{mmol}$, $10 \mathrm{mCi} / \mathrm{ml}(370 \mathrm{mBq} / \mathrm{ml}), 50 \mathrm{mM}$ Tricine $(\mathrm{pH}$ 7.6) (Perkin Elmer)

\section{BUFFERS AND SOLUTIONS FOR HYBRIDIZATION ANALYSIS}

- EDC fixation solution $(24 \mathrm{ml})$

$245 \mu \mathrm{l}$ of $12.5 \mathrm{M}$ methylimidazole, $\mathrm{pH} 8.0$

$0.5 \mathrm{~g} \mathrm{EDC}$

- Wash solution

2x SSC

$0.1 \%$ SDS

\section{TISSUE PRINT}

The samples were washed and dried at room temperature. The samples were cut in longitudinal and/or transverse sections. After cutting the samples, they were immediately placed with the cut surface face down on the membrane (Amersham Hybond-N; GE Healthcare). The different sections were firmly pressed on the nylon membrane for $30 \mathrm{~s}$, subsequently the tissue was carefully removed and the membrane was dried (around 5-20 min) at room temperature.

\section{FIXATION OF THE MEMBRANE}

The EDC fixation solution was prepared as describe Pall and Hamilton (2008) with some modifications. Briefly, $0.753 \mathrm{~g}$ of EDC was dissolved in $10 \mathrm{ml}$ of water, $245 \mu \mathrm{l}$ of $12.5 \mathrm{M} 1$ methylimidazole was added and finally $150 \mu \mathrm{l}$ of $1 \mathrm{M} \mathrm{HCl}$ was added to obtain a $\mathrm{pH}$ of 8 . This solution was prepared fresh before use. The membranes were incubated in this fixation solution for $1 \mathrm{~h}$ at $65^{\circ} \mathrm{C}$, and then rinsed twice with water. The membranes were dried at room temperature, and stored at $-20^{\circ} \mathrm{C}$ till further use. miRNA detection was carried out as the hybridization analysis.

\section{HYBRIDIZATION ANALYSIS}

To prepare the probes we used the following synthesized oligonucleotides, which sequences are complementary to each 21 nucleotide mature miRNA of interest: $5^{\prime}$-AGGGGCCATGCTAA TCTTCTC-3', 5' -AAGAGCT CCCTTCAATCCAAA-3', 5'-UGGA GAAGCAGGGCACGUGCA-3' , and 5' -TGCACGTGCCCTGCTT CTCCA-3', to detect the small nucleolar RNA U6 (positive control), miR159a, miR164, and miR164* sense (negative control), respectively. The small nucleolar RNA U6 is often used as a loading control or used for signal normalization (e.g., Kou et al., 2012; Rosas-Cárdenas et al., 2015). To prepare the probes the oligonucleotides were labeled as follows: $4 \mu \mathrm{l}$ of oligonucleotide $100 \mu \mathrm{M}$, $1 \mu \mathrm{l}$ of T4 Kinase $(10 \mathrm{U} / \mu \mathrm{l}), 1 \mu \mathrm{l}\left[\gamma_{-}{ }^{32} \mathrm{P}\right]$ ATP $(10 \mathrm{mCi} / \mathrm{ml}), 4 \mu \mathrm{l}$ of forward buffer and $10 \mu \mathrm{l}$ of water; the reaction solutions were incubated at $37^{\circ} \mathrm{C}$ for $1 \mathrm{~h}$ and subsequently added to the membranes. The hybridization was made as we described before in Rosas-Cárdenas et al. (2011) with some modifications. In summary, the used hybridization solution was the Rapid-hyb buffer (GE healthcare), which contains chemical blocking agents and therefore does not require heterologous DNA to control nonspecific binding of probes to the membrane. The membranes were pre-hybridized with $15 \mathrm{ml}$ hybridization solution for $1 \mathrm{~h}$ at $42^{\circ} \mathrm{C}$ with constant agitation, followed by adding the labeled probe of interest, and then incubated for $24 \mathrm{~h}$ at $42^{\circ} \mathrm{C}$ with constant agitation. Membranes were washed with wash solution (2x SSC, $0.1 \%$ SDS), first for $4 \mathrm{~min}$, and afterwards for $2 \mathrm{~min}$ at room temperature, followed by exposure to a storage phosphor screen for $24 \mathrm{~h}$ and/or $48 \mathrm{~h}$ at room temperature (highly expressed miRNAs can be detected already at $12 \mathrm{~h}$ ). Finally, the storage phosphor screen was scanned in a Storm $860 \mathrm{Gel}$ and Blot Imaging System (Amersham Biosciences). This protocol is not yet tested with the use of non-radioactive probes, but we expect it to work.

\section{SUMMARY: TISSUE PRINTING HYBRIDIZATION PROTOCOL}

1. Cut a membrane to the appropriate size.

2. Cut the tissue and carefully place a longitudinal and/or a transverse section(s) onto the membrane with the cut surface down and firmly press the tissue for $30 \mathrm{~s}$.

3. Carefully remove the tissue from the membrane.

4. Dry the membrane at room temperature.

5. Fix the membrane with EDC solution for $1 \mathrm{~h}$ at $65^{\circ} \mathrm{C}$.

6. Rinse the membrane with water and then dry it at room temperature.

7. Pre-hybridize the membrane with $15 \mathrm{ml}$ hybridization solution for $1 \mathrm{~h}$ at $42^{\circ} \mathrm{C}$ with constant agitation.

8. Add the labeled probe of interest and incubate for 3-24 h at $42^{\circ} \mathrm{C}$ with constant agitation.

9. Discard the hybridization solution and wash the membrane with wash solution for $4 \mathrm{~min}$ at room temperature.

10. Discard the wash solution and wash the membrane again for $2 \mathrm{~min}$ at room temperature.

11. Expose the membrane to a storage phosphor screen for $24 \mathrm{~h}$ at room temperature and then scan the screen and analyze the signal.

\section{RESULTS AND DISCUSSION}

In this work we aimed to develop an easy protocol that would allow the in situ detection of miRNAs in relatively large plant tissues or organs. For this we used the combination of tissue printing and hybridization. Tissue printing is a simple procedure by which the uppermost layer of cells and the surrounding extracellular matrix of the cut surface from plant tissue are transferred to a membrane after physical contact with the membrane surface generating a bidimensional anatomical image on which the molecule of interest can be visualized by hybridization. The procedure is depicted in Figure 1 as a flow diagram consisting of three steps: tissue print, membrane fixation, and miRNA detection. The detailed procedure is described in Section "Materials and Methods." We used this tissue printing hybridization protocol to observe the 


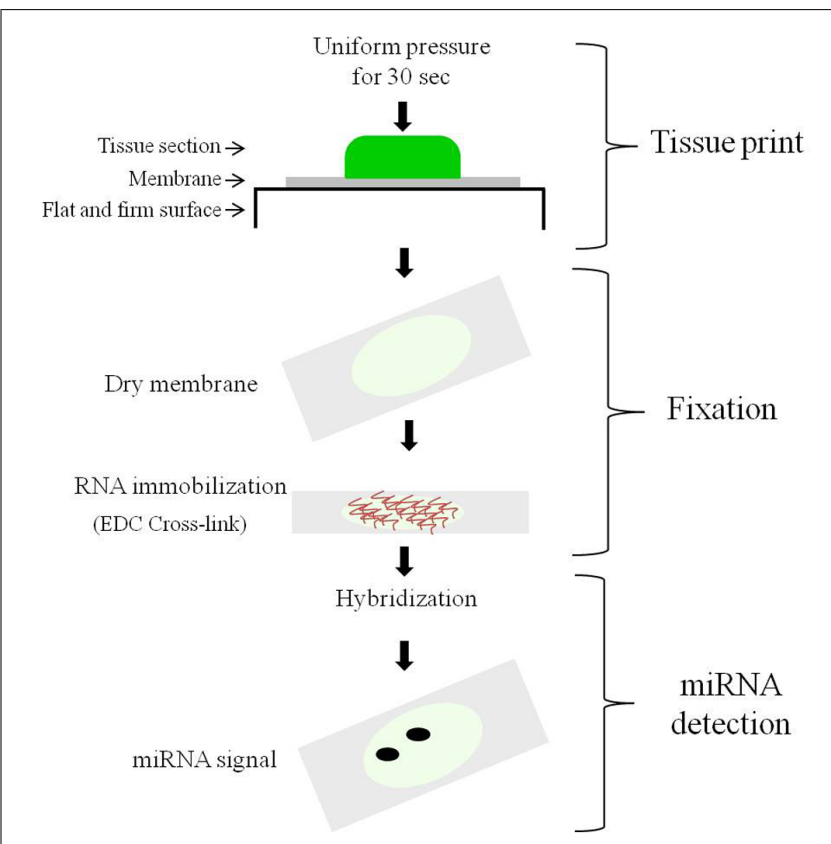

FIGURE 1 |The procedure of the tissue printing hybridization protocol. The diagram illustrates the main steps: (1) The tissue printing step; (2) the membrane fixation step; and (3) the hybridization detection step.

spatio-temporal expression of miR159 and miR164 in different tissues (Figures 2-4 and Supplementary Figure S1), as described below.

\section{DETECTION OF miRNAs BY TISSUE PRINTING HYBRIDIZATION}

We first tried the protocol with a green tomato fruit (Figure 2A). A transverse cut of the tomato fruit was made (Figure 2B), which was then firmly pressed on the membrane, leaving a faint tissue print behind on the membrane (Figure 2C). The membrane was then hybridized with a ${ }^{32} \mathrm{P}$ labeled probe against miR164 (Figure 2D) and an independently printed membrane hybridized with a probe against the nucleolar U6 (positive control) (Figure 2E), and with a miR164 sense probe (negative control; Supplementary Figure S2). A strong miR164 signal was observed in seeds, a signal in the exocarp and/or mesocarp, and a moderate signal in the endocarp, in line with observed expression in complete tomato fruits (Moxon et al., 2008). The U6 signal was also clearly observed in the seeds and a lower signal in the pericarp tissues. Notably, the nucleolar U6 signal may also change during development, as previously reported (e.g., Kou et al., 2012).

Subsequently, we repeated the miR164 detection in different fruit crops, now in strawberry (botanically speaking not a berry), guava, and again tomato, but for each two different developmental stages were used (Figure 3). Again, the strongest hybridization signal can be observed in seeds and a lower expression in pericarp tissues. Notably, a clear signal can be seen from the seeds that are on the outside in the case of strawberry (Figure 3).

Furthermore, we also tried floral buds to see if we could detect signal for miR164 and for miR159. We used transverse cuts of two developmental stages of floral buds from agave to make the tissue prints (Figure 4). We observed signal for both miRNAs, for miR164 mostly in placenta/transmitting tract tissue and for miR159 mostly in ovules.
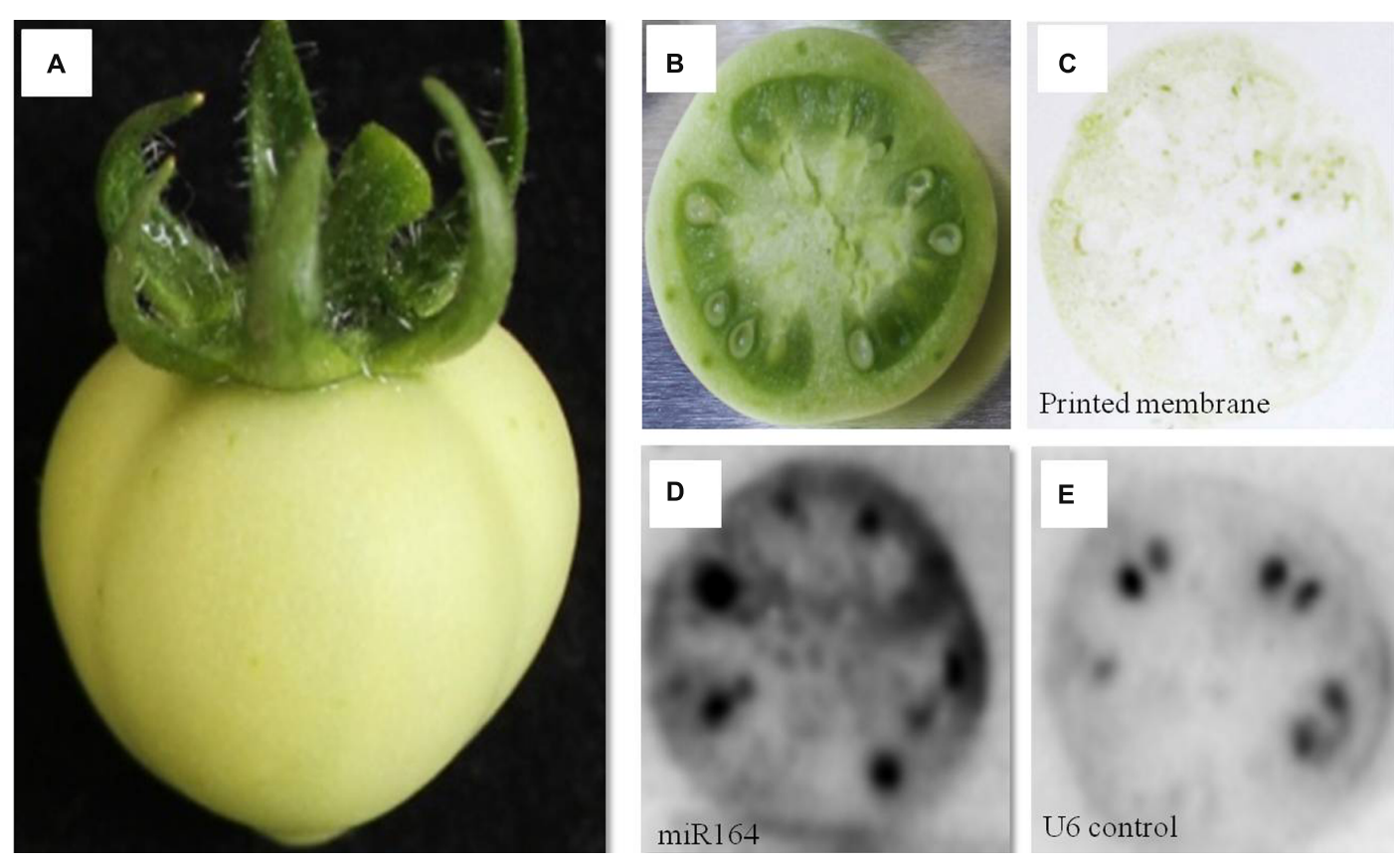

FIGURE 2 I miR164 detection by tissue printing hybridization in tomato fruit. (A) Tomato fruit; (B) Transverse cut tomato fruit to be used for the tissue printing; (C) Tissue print on the membrane made from a transverse cut tomato fruit; (D) miR164 detection by hybridization; (E) nucleolar U6 (positive control) detection by hybridization. 

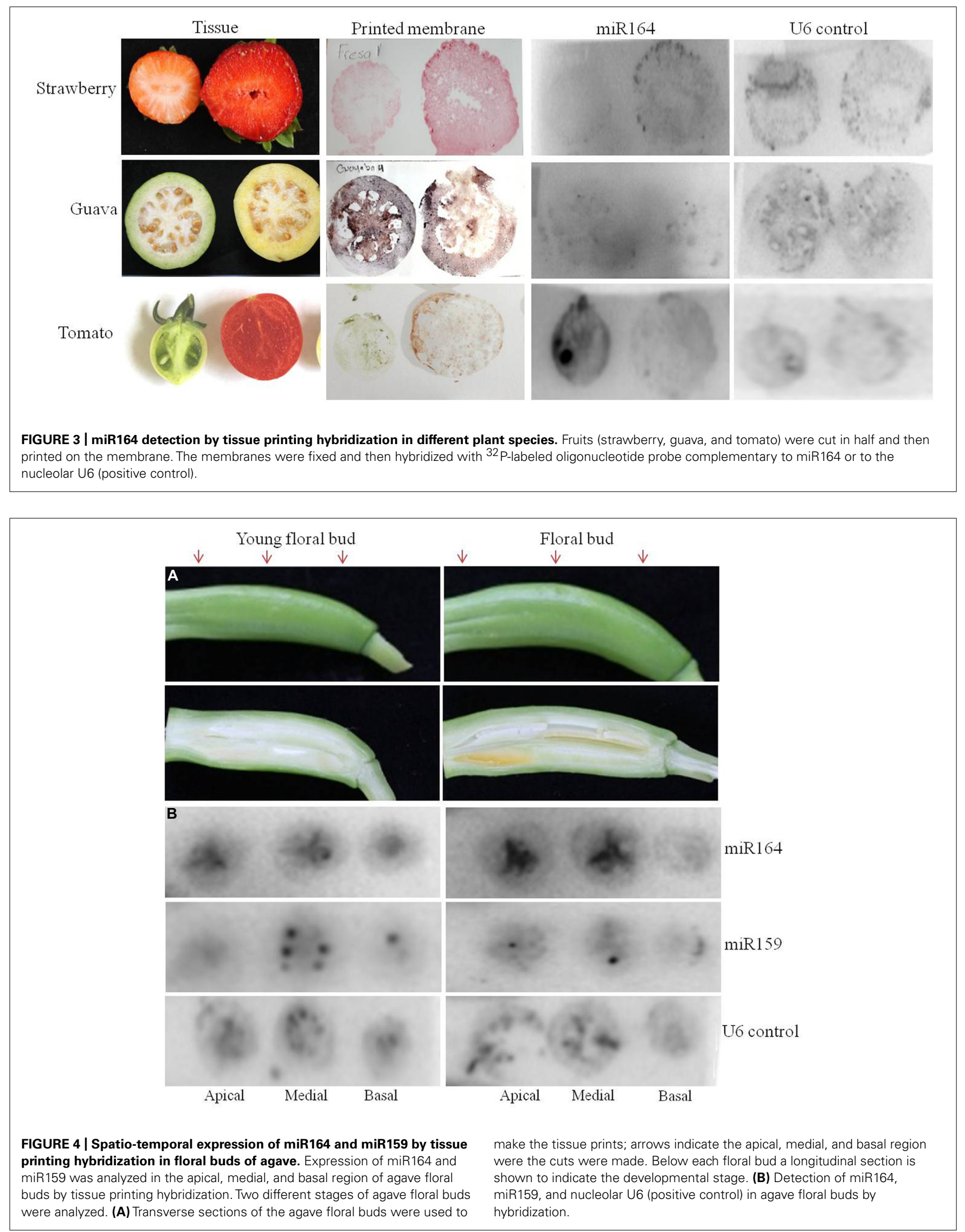
The observed hybridization patterns in the different experiments for miR164, miR159, and nucleolar U6 are different, indicating that the observed signals are not background. Notably, when we used banana fruit for the tissue print, which left a lot of tissue behind on the membrane, we observed signal for the probe against miR164, but also for the sense miR164 negative control (Supplementary Figure S1). For the tissue prints of the other fruits no signal was observed with the miR164 sense probe (Supplementary Figure S2). So, caution should be taken with making conclusions when printing very soft tissues. However, we cannot exclude the possibility that miR164* in banana fruit is stable and detectable, as the detection of some other miRNA*s has been reported (Zhang et al., 2011; Manavella et al., 2013). A possibility is to use another miRNA sense probe to distinguish between background and real signal.

\section{DETECTION OF mIRNAs IN FRUIT JUICE BY DOT BLOT HYBRIDIZATION}

Sometimes it might not be important to know exactly where in the tissue the miRNA is expressed, but for instance just presence or absence, which could be useful to analyze genetically modified crops. We reasoned that it should be possible to detect miRNA expression in fruit juice (or crude extract). For this we prepared membranes with $5 \mu \mathrm{l}$ fruit juice of lemon, mandarin, prickly pear cactus fruit, and tomato fruit. After applying the juice to the membrane, the membranes were fixed and then hybridized with the probe against miR164 (Figure 5A). Indeed, a clear signal was observed for miR164 as well as for the positive control U6. Furthermore, we tried fruit juice of three different developmental stages of tomato fruits and hybridized it with the probe against miR159 (Figure 5B). Also for miR159 a clear signal was observed, which was the highest in the youngest fruit stage, suggesting that miR159 is more expressed at that stage. In summary, this is an alternative way to quickly detect the expression of a miRNA.

\section{CONCLUSION}

Here we provide a simple, rapid, and useful protocol to detect miRNAs from different tissues and organs of plant species. Using this tissue printing hybridization protocol we were able to determine the spatial-temporal expression pattern of miR159 and miR164 in different tissues. Moreover, we showed the possibility to detect the expression of miRNAs in fruit juice using a dot blot hybridization approach. This allows for instance the semi-high throughput
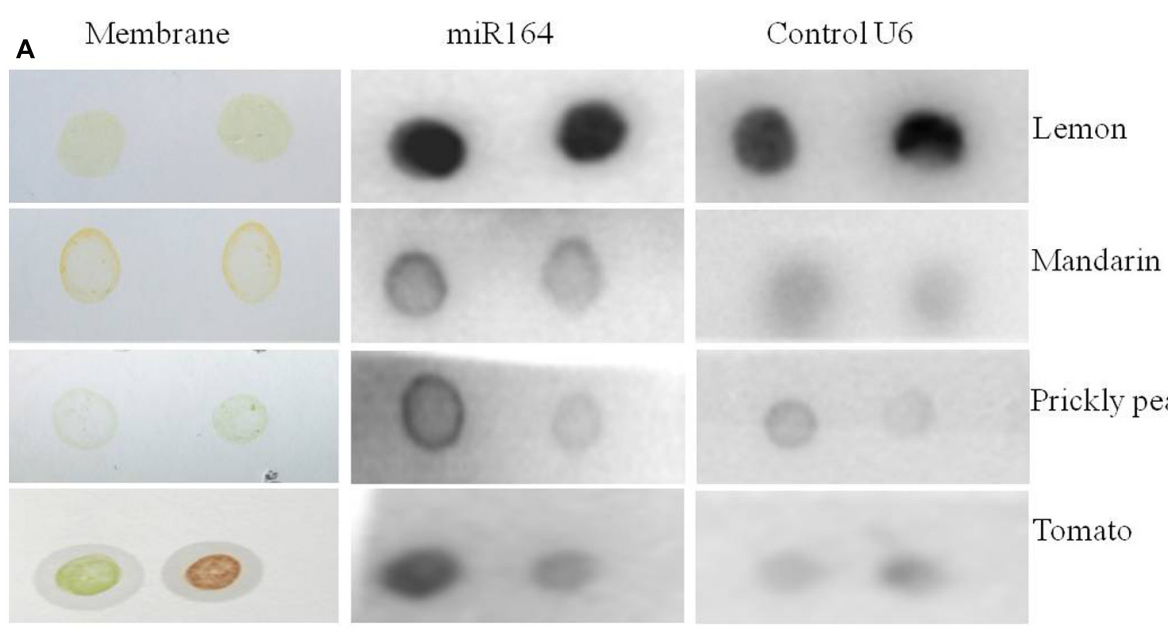

B

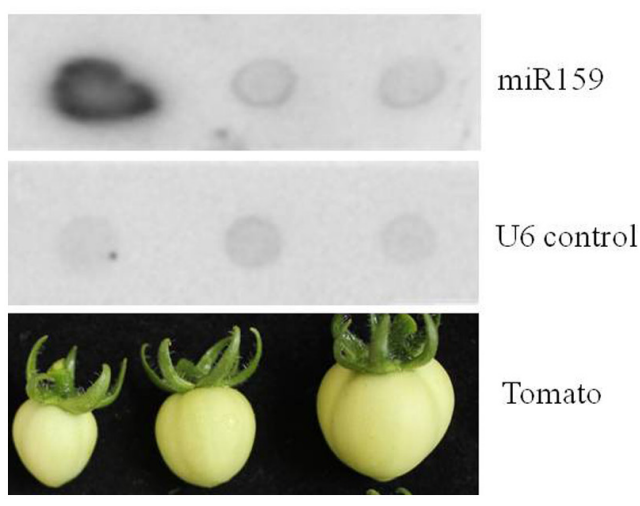

FIGURE 5 | miR164 and miR159 detection in fruit juices of different plant species by dot blot hybridization. Five microliter of fruit juice were spotted on membranes and the miRNAs were detected by hybridization assays. (A) Expression of miR164 in lemon and mandarin juice, and in crude extract of green and ripe stages of prickly pear cactus and tomato fruits. (B) Expression of miR159 in different developmental stages of tomato crude extracts. The tomato fruit stages used for the crude extracts are shown below the membrane. 
screening for the presence of a miRNA in fruits when no tissue localization is required.

\section{AUTHOR CONTRIBUTIONS}

FFRC did the major experimental work. REG contributed to the hybridization assays. FFRC, ACH, NMM, and SDF conceived the project and designed the experiments. FFRC and SDF drafted the manuscript. All authors read and approved the final manuscript.

\section{ACKNOWLEDGMENTS}

We thank Dr. June K. Simpson Williamson for providing Agave material. We thank MSc. Karla L. Gonzalez-Aguilera for support in the laboratory. We also thank the Mexican National Council of Science and Technology (CONACyT) for a Ph.D. fellowship to FFRC (199450). This work in the de Folter laboratory was financed by the CONACyT grant 177739.

\section{SUPPLEMENTARY MATERIAL}

The Supplementary Material for this article can be found online at: http://www.frontiersin.org/journal/10.3389/fpls.2015.00099/ abstract

\section{REFERENCES}

Chavez Montes, R. A., Rosas-Cárdenas, F. F., De Paoli, E., Accerbi, M., Meyers, B. C., Rymarquis, L. A., et al. (2014). Sample sequencing of vascular plants demonstrates widespread conservation and divergence of microRNAs. Nat. Commun. 5, 3722. doi: $10.1038 /$ ncomms4722

Chen, C., Ridzon, D. A., Broomer, A. J., Zhou, Z., Lee, D. H., Nguyen, J. T., et al. (2005). Real-time quantification of microRNAs by stem-loop RT-PCR. Nucleic Acids Res. 33, e179. doi: 10.1093/nar/gnil78

Esteves, F., Teixeira Santos, M., Eiras-Dias, J. E., and Fonseca, F. (2013) Molecular data mining to improve antibody-based detection of Grapevine leafroll-associated virus 1 (GLRaV-1). J. Virol. Methods 194, 258-270. doi: 10.1016/j.jviromet.2013.09.004

Holland, N., Holland, D., Helentjaris, T., Dhugga, K., Beatriz, X.-C., and Delmer, D. P. (2000). A comparative analysis of the plant cellulose synthase (CesA) gene family. Plant Physiol. 123, 1313-1323. doi: 10.1104/pp.123.4.1313

Jolie, R. P., Duvetter, T., Vandevenne, E., Van Buggenhout, S., Van Loey, A. M., and Hendrickx, M. E. (2010). A pectin-methylesterase-inhibitor-based molecular probe for in situ detection of plant pectin methylesterase activity. J. Agric. Food Chem. 58, 5449-5456. doi: 10.1021/jf100248u

Kidner, C., and Timmermans, M. (2006). In situ hybridization as a tool to study the role of microRNAs in plant development. Methods Mol. Biol. 342, 159-179. doi: 10.1385/1-59745-123-1:159

Kou, S. J., Wu, X. M., Liu, Z., Liu, Y. L., Xu, Q., and Guo, W. W. (2012). Selection and validation of suitable reference genes for miRNA expression normalization by quantitative RT-PCR in citrus somatic embryogenic and adult tissues. Plant Cell Rep. 31, 2151-2163. doi: 10.1007/s00299-012-1325-x

Manavella, P. A., Koenig, D., Rubio-Somoza, I., Burbano, H. A. Becker, C., and Weigel, D. (2013). Tissue-specific silencing of Arabidopsis SU(VAR)3-9 HOMOLOG8 by miR171a. Plant Physiol. 161, 805-812. doi: $10.1104 /$ pp. 112.207068
Mochizuki, T., and Ohki, S. T. (2015). Detection of plant virus in meristem by immunohistochemistry and in situ hybridization. Methods Mol. Biol. 1236, 275287. doi: 10.1007/978-1-4939-1743-3_20

Moxon, S., Jing, R., Szittya, G., Schwach, F., Rusholme Pilcher, R. L., Moulton, V., etal. (2008). Deep sequencing of tomato short RNAs identifies microRNAs targeting genes involved in fruit ripening. Genome Res. 18, 1602-1609. doi: 10.1101/gr.080127.108

Pall, G. S., and Hamilton, A. J. (2008). Improved northern blot method for enhanced detection of small RNA. Nat. Protoc. 3, 1077-1084. doi: 10.1038/nprot.2008.67

Pluskota, W. E., Bradford, K. J., and Nonogaki, H. (2011). Tissue-printing methods for localization of RNA and proteins that control seed dormancy and germination. Methods Mol. Biol. 773, 329-339. doi: 10.1007/978-1-61779-231-1_19

Qu, L. Q., Tada, Y., and Takaiwa, F. (2003). In situ western hybridization: a new, highly sensitive technique to detect foreign and endogenous protein distribution in rice seeds. Plant Cell Rep. 22, 282-285. doi: 10.1007/s00299-003-0683-9

Rosas-Cárdenas, F. F., Caballero-Pérez, J., Ramos, X. G., Cruz-Hernández, A., Marsch-Martínez, N., and de Folter, S. (2015). miRNA expression during prickly pear cactus fruit development. Planta 241, 435-448. doi: 10.1007/s00425-0142193-0

Rosas-Cárdenas, F. F., Durán-Figueroa, N., Vielle-Calzada, J. P., Cruz-Hernández, A., Marsch-Martínez, N., and de Folter, S. (2011). A simple and efficient method for isolating small RNAs from different plant species. Plant Methods 7, 4. doi: 10.1186/1746-4811-7-4

van Rooij, E. (2011). The art of microRNA research. Circ. Res. 108, 219-234. doi: 10.1161/CIRCRESAHA.110.227496

Várallyay, É., and Havelda, Z. (2011). Detection of microRNAs in plants by in situ hybridisation. Methods Mol. Biol. 732, 9-23. doi: 10.1007/978-1-61779-083-6_2

Varner, J. E., and Ye, Z. (1994). Tissue printing. FASEB. J. 8, 378-384.

Voinnet, O. (2009). Origin, biogenesis, and activity of plant microRNAs. Cell 136, 669-687. doi: 10.1016/j.cell.2009.01.046

Yin, J. Q., Zhao, R. C., and Morris, K. V. (2008). Profiling microRNA expression with microarrays. Trends Biotechnol. 26, 70-76. doi: 10.1016/j.tibtech.200 7.11.007

Zhang, X., Zhao, H., Gao, S., Wang, W. C., Katiyar-Agarwal, S., Huang, H. D., et al. (2011). Arabidopsis argonaute 2 regulates innate immunity via miRNA393(*)mediated silencing of a Golgi-localized SNARE gene, MEMB12. Mol. Cell 42, 356-366. doi: 10.1016/j.molcel.2011.04.010

Conflict of Interest Statement: The authors declare that the research was conducted in the absence of any commercial or financial relationships that could be construed as a potential conflict of interest.

Received: 17 December 2014; accepted: 06 February 2015; published online: 03 March 2015.

Citation: Rosas-Cárdenas FF, Escobar-Guzmán R, Cruz-Hernández A, MarschMartinez $N$ and de Folter $S$ (2015) An efficient method for miRNA detection and localization in crop plants. Front. Plant Sci. 6:99. doi: 10.3389/fpls.2015.00099

This article was submitted to Plant Biotechnology, a section of the journal Frontiers in Plant Science.

Copyright (c) 2015 Rosas-Cárdenas, Escobar-Guzmán, Cruz-Hernández, MarschMartinez and de Folter. This is an open-access article distributed under the terms of the Creative Commons Attribution License (CC BY). The use, distribution or reproduction in other forums is permitted, provided the original author(s) or licensor are credited and that the original publication in this journal is cited, in accordance with accepted academic practice. No use, distribution or reproduction is permitted which does not comply with these terms. 